\title{
Dietary and Physical Activity Modifications Intervention for Older People
}

\author{
Trias Mahmudiono ${ }^{1}$, Stefania Widya Setyaningtyas ${ }^{1}$, Qonita Rachmah ${ }^{1}$, Mahmud Aditya Rifqi ${ }^{1}$, Diah Indriani ${ }^{2}$, \\ Triska Susila Nindya ${ }^{1}$, Hario Megatsari ${ }^{3} \&$ Wantanee Kriengsinyos ${ }^{4}$ \\ ${ }^{1}$ Departement of Nutrition, Faculty of Public Health, Universitas Airlangga, Jl. Mulyorejo Kampus C, Surabaya, \\ Indonesia \\ ${ }^{2}$ Departement of Biostatistic dan Demography, Faculty of Public Health, Universitas Airlangga, Jl. Mulyorejo \\ Kampus C, Surabaya, Indonesia \\ ${ }^{3}$ Departement of Health Promotion and Behavioral Sciences, Faculty of Public Health, Universitas Airlangga, Jl. \\ Mulyorejo Kampus C, Surabaya, Indonesia \\ ${ }^{4}$ Insitute of Nutrition, Mahidol University, Nakhon Pathom, Thailand \\ Correspondence: Trias Mahmudiono, Department of Nutrition, Faculty of Public Health, Universitas Airlangga, \\ Jl. Mulyorejo Kampus C, Surabaya 60115, Indonesia. Tel: 62-31-5964808 E-mail: trias-m@fkm.unair.ac.id
}

Received: November 12, 2018 Accepted: January 10, 2019 Online Published: January 15, 2019

doi:10.5539/gjhs.v11n2p70 URL: https://doi.org/10.5539/gjhs.v11n2p70

\begin{abstract}
Objective: Diet and physical activity modification such as specialized gymnastic, Taichi, or yoga could reduce either blood glucose or HbA1C level in diabetes patients among older people. This study was a behaviorally based nutrition education intervention for older people in reducing their $\mathrm{HbA} 1 \mathrm{C}$ and total cholesterol level in urban area in Indonesia.
\end{abstract}

Design: This was quasi experimental study with three-month behavioral intervention based on Social Cognitive Theory.

Setting: The study was held in Jagir Sub-district located in urban area of Surabaya. Preliminary study showed proportion of hypercholesterolemia and diabetes mellitus among older people in Jagir Sub-district was respectively $21.37 \%$ and $2.74 \%$.

Participants: 60 older people in Jagir Sub-district was divided into 5 groups consist of: control, physical activity education only, nutrition education only, combination of physical activity and nutrition education, and education material only group.

Interventions: The intervention was consisted of six sessions physical activity or nutrition education, or both of it performed by trained nutrition science students.

Main Outcome Measures: The primary outcomes of this study were HbA1C (\%) and total cholesterol (mg/dL) levels.

Analysis: The normal distributed or transformed data was analyzed using mixed factorial ANOVA in order to test the difference between groups.

Keywords: nutrition education, diabetes mellitus, elderly, Indonesia

\section{Introduction}

The number of older people had been predicted to increase from 524 million in 2010 to become 1.5 billion in 2050 (WHO, 2011). This trend is also captured in Indonesia. In 2014, Indonesia was noted to have as much as 18,781 million older people. This number is predicted to be doubled up to 36 million in 2025 (Badan Pusat Statistik, 2014; Departemen Kesehatan Republik Indonesia, 2015). In Indonesia, degenerative diseases have become a cause of 6 out of 10 mortality cases, and about a half was caused by cardiovascular diseases (Departemen Kesehatan Republik Indonesia, 2015). Diabetes mellitus is one kind of degenerative diseases that is commonly found in older people. In Unites States, prevalence of older people with diabetes were about $22-33 \%$, depends on diagnostic criteria. In South East Asia region, there was also significant increase of diabetes mellitus. In Thailand for example, 
prevalence of diabetes was $8 \%$, and in Indonesia, there was $6.2 \%$ diabetes cases, where $50 \%$ of cases occurred in $>65$ years old people (International Diabetes Federation, 2015a, 2015b; Kurniawan, 2010). There are many factors that are involved in pathogenesis of diabetes, include lack dietary behavior and low physical activity ((WHO) World Health Organization \& International Society of Hypertension Writing Group, 2003; Hu, 2003, 2011; Shi et al., 2013; Siri-Tarino, Sun, Hu, \& Krauss, 2010; Waxman, 2005).

Nutrition transition that change food production, transportation, marketing, mass media, and other aspects that would influence food availability and might shift the food choices and dietary pattern (Popkin, Adair, \& Ng, 2013). Some believe that nutrition transition was a catalyst for the rise of diabetes mellitus in developing countries. A study in Asia showed that there was an increase in processed food consumption which rich in salt, sugar, and fat in low- middle-income countries in Asia (Baker \& Friel, 2014). The sugar consumption has been proved to be independent risk factor for diabetes mellitus in low-, middle-income countries which was driven by urbanization and income increment (Basu, Stuckler, Mckee, \& Galea, 2012). High glycemic index intakes are one of risk factor for either diabetes mellitus or cardiovascular disease. Besides high carbohydrates content, high glycemic index diet also gives an impact on metabolic responses such as reactive hypoglycemic, counter regulation of hormone secretion, and elevated of blood free fatty acid. Those metabolic responses might lead to beta cell impairment, dyslipidemia, and endothelial dysfunction (Ludwig, 2002). Several studies showed low glycemic index diet could give beneficial effects, not only reduced diabetes marker such as fasting blood glucose and $\mathrm{HbA1C}$, but also enhanced other metabolic marker such as total cholesterol, triglycerides, and LDL cholesterol profiles in the blood (Brand-Miller, Hayne, Petocz, \& Colaiguri, 2003; Goff, Cowland, Hooper, \& Frost, 2013; Wang, Xia, Zhao, \& Zhang, 2015).

The behavioral changes in older people can be approached by increase of self-efficacy to maintain blood glucose and cholesterol levels. Self-efficacy enhancement can be powerful factor to motivate people to modify their lifestyle, including dietary and physical activity patterns. In social cognitive theory approaches, the self-efficacy can be built by mastery experience, verbal motivation, and vicarious experience (role modeling) (Bandura, 1989). Previous nutrition education intervention showed promising results in the management of diabetic patients. A study which used glycemic index diet as educational material showed better improvement compared to nutrition education using conventional diabetes diet material. This result might be influenced by the shape of information towards glycemic index that was made simpler and easy to be understood (Frost, Wilding, \& Beecham, 1994). The use of "traffic light" system can be considered as a novel communication strategy to deliver food and nutritional information related to diseases since people already pre-disposed to the idea of "traffic light". The color code in "traffic light" approach could lead to better understanding as compare to common nutrition information such as the use nutrition facts (Drichoutis, Lazaridis, \& Nayga, 2006).

Besides dietary pattern, World Health Organization (2011) (WHO, 2011) also stated that low physical activity brings about at least 800.000 death in South East Asia Region. A meta-analysis study showed that any kind of physical activity would give beneficial effects on reduction of type 2 diabetes and cardiovascular diseases risk (Aune, Norat, Leitzmann, Tonstad, \& Vatten, 2015; Cooper et al., 2014; Rasiah et al., 2015). A simple and easy sport activity did not require special equipment such as Radio Taiso in Japan was significantly improving physical performance related to fall risk factors such as static balance, flexibility, agility, and muscle strength among older people if performed at least five times per week (Kawagoe et al., 2010). However, randomized controlled trial (RCT) studies measuring the effectiveness of Radio Taiso intervention among elderly outside Japanese population was scare.

Based on scarcity of evidence related to the effectiveness of nutrition education targeting diet and physical activity modification such as engaging in Radio Taisho, this study aimed to analyze the effectiveness of nutrition education in dietary and physical activity modifications for HbA1C and cholesterol control among older people in Jagir Public Health Centre, Surabaya.

\section{Method}

This field quasi experimental consisted of 5-arm parallel groups (a control group, physical activity education only group, nutrition education only group, combination of physical activity and nutrition education group, and education material only group). A three-month behavioral intervention was delivered to 3 groups (physical activity education only group, nutrition education only group, combination of physical activity and nutrition education group). After an initial screening procedure, 60 older people who lived in Jagir Sub-district, Surabaya were chosen to be assigned to 5 groups of the research. Each group consists of 12 respondents who received different kind of intervention at the same duration. Baseline data was gathered from participants in their homes at the beginning of the study. Another visit to collect post-intervention data followed the three-month intervention. The adapted 
CONSORT diagram in Figure 1 showed progression through the study for individual participants.

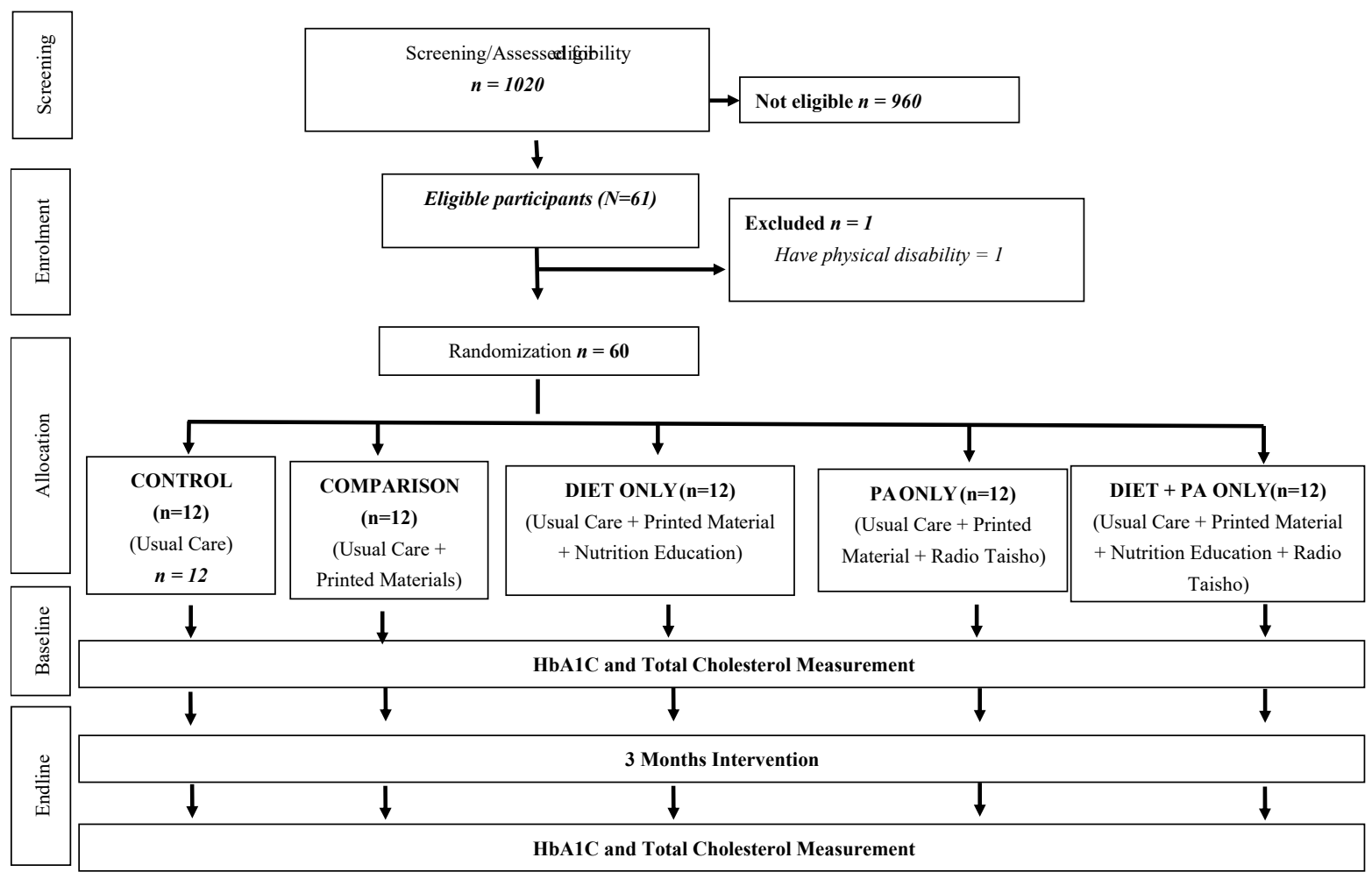

Figure 1. Adapted CONSORT diagram of the study

\subsection{Objective and Hypothesis}

The objective of the RCT was to evaluate the effectiveness of a behaviorally based nutrition and physical activity education to manage $\mathrm{HbA1C}$, cholesterol, and blood pressure levels in older people at coverage area of Jagir Public Health Center Surabaya. We hypothesized that after six sessions of behaviorally based nutrition education, relative to the comparison group, older people in the intervention group would increase their fruit and vegetables intake, dietary adherence based on traffic light diet, physical activity, and sedentary time.

\subsection{Institutional Review Board}

This research was approved by the Institutional Review Board (IRB) at the Faculty of Public Health, Universitas Airlangga on July 25, 2017 with reference or proposal number: 414-KEPK. Trial was approved by the Surabaya City Review Board (Bakesbangpol No: 070/6275/436.8.5/2017) in Indonesia. Only the participants who signed the consent to show their agreement to take part in blood drawing and intervention was included in the study. The Universal Trial Number (UTN) for this study is U1111-1199-9899. This trial has been registered at the Thai Clinical Trials Registry (TCTR) with study ID: TCTR20171124001 in November, 24 2017. The TCTR is recognized as an ICMJE (the International Committee of Medical Journal Editors) acceptable registry and a Primary Registry in the WHO registry network.

\subsection{Setting}

The study was held in Surabaya, Indonesia, one of largest urban city with varied demographic composition in Indonesia (Badan Pusat Statistik Kota Surabaya, 2015). According to Popkin (2013) (Popkin et al., 2013), urbanization is resulted in sedentary lifestyle and increase of food availability and food choices, that could lead to increase intake empty energy food. Preliminary study showed proportion of hypercholesterolemia and diabetes mellitus among older people in Jagir Sub-district was respectively $21.37 \%$ and $2.74 \%$. Surabaya becomes a representative of urban area in Indonesia because this city has variety range of population densities, urbanization, and socioeconomic profiles (VK, JK, \& R., 2014). 


\subsection{Target Population}

The population of this study was 1020 older people in Jagir Sub-districts who's registered in elderly community health posts ("posyandu lansia"). The purposive sampling was done by choose subjects who have high blood glucose and/or cholesterol levels. Twelve chosen participants at 5 cluster community health posts for older people (Posyandu Lansia) were given informed consent before undergoing screening to validate their eligibility for participation. The case definition included high HbA1C level $(\geq 6,5 \%)$ based on American Diabetes Association (2014) criteria for diagnosis of diabetes and/or high level of total blood cholesterol ( $\geq 200 \mathrm{mg} / \mathrm{dl}$ ) based on NCEP III ATP criteria [NCEP 2002]. Repeated anthropometric and blood pressure measurement for participants both were performed by trained research assistance in posyandu lansia. A third measurement was initiated when the discrepancy between the first and the second measurement was greater than $1 \%$.

\subsection{Inclusion and Exclusion Criteria}

Inclusion criteria for participants of this study were: fluent in conventional Bahasa Indonesia, a permanent resident planning to stay in Surabaya City for at least six months, aged more than 65 years old, registered in posyandu lansia and had history of suffering diabetes and/or dyslipidemia. Participants were excluded in cases where either had physical disability, they had to follow diet that counterpart with traffic light diet due to other diseases such as chronic kidney diseases and chronic pulmonary diseases, or dead.

\subsection{Power Calculation}

Previous lifestyle modification study in Malaysia showed intervention gave an effect on lifestyle changes as big as 0.56 . Based on that study, using $90 \%$ of power to detect changes in individual level, the minimal sample size was 36 older people with 0.05 two-tailed alphas. With assumption of drop rate as much as $10 \%$, the minimal total sample was 40 subjects. Basic Health Research (2013) showed prevalence of diabetes mellitus in Indonesia was $6.2 \%$. With those considerations, it was expected around 60 elderly with diabetes mellitus identified and disposed to be involved in this research.

\subsection{Randomization and Allocation Concealment}

Randomization of participants was performed using a clustered random sampling technique which was done using computer to generate random numbers. After assignment of random numbers to the 5 cluster, the list was sorted based on the random number. First upper rank was assigned to the control group; the second was assigned to physical activity education only group; the third, fourth and the last rank group were respectively assigned to nutrition education only group, combination of physical activity and nutrition education group, and education material only group.

\subsection{Intervention}

The framework underlying this study was Bandura's Social Cognitive Theory (SCT). The SCT is a method of behavior change through modification to determinants that influence person's choice of action, encompasses individual, environment, and and behavior interaction (Bandura, 1989). In the present study, older people behavioral change related to traffic light diet and physical activity may be influenced by self-efficacy for enhancing consumption of lower glycemic index food such as fruits and vegetables in the daily menu, and for increasing physical activity duration and frequency. The SCT approach assumes that the presence of others influences the change in one's behavior. In presents study, nutrition education materials, including booklets for all participants, were developed based on the constructs of Social Cognitive Theory (SCT) (Figure 2). This study addressed several means of enhancing older people's self-efficacy such as mastery of making a healthy menu for diabetes and dyslipidemia, peer group modeling of older people towards feeding practices or engaging in physical activity and incorporating fruits and vegetables in daily meals. Expected behavioral outcomes of this study were enhancing both dietary and physical activity pattern among older people. In order to enhance dietary pattern, the target behavior was increased low glycemic index food as well as fruits and vegetable. To enhance physical activity pattern, the target behavior was increased duration and frequency of physical activity.

Manuals of both diabetes and dislipidemia care published in Bahasa Indonesia or in English in the last ten years were summarized to gain information of low glycemic and low cholesterol food as well as to physical activities. Both peer-reviewed articles and gray literature were located and translated into Bahasa Indonesia. The researchers then string up the reference to become traffic light guide of glycemic index and cholesterol level of food and also radio-taisho guide. The educational material is translated to a simple animation picture to facilitate elderly to understand the educational material. Manuals were drafted and refined through a lengthy review process and will be used as the printed educational materials for the intervention. 
The intervention group received various kind of treatment. The diet and physical activity group, the diet only group, and the comparison group received printed educational material consisted of traffic light diet on glycemic index and cholesterol in food. In addition, a modules of physical activity modules were also given to all group except control group and diet only group. The modules were arranged based on Bandura's Social Cognitive Theory construct with simplified language to describes dietary and physical activity strategies to improve the health state of older people with diabetes and/or dyslipidemia. Besides modules, older people in groups which were given physical activity modules also taught to practice radio-taiso twice during the sessions

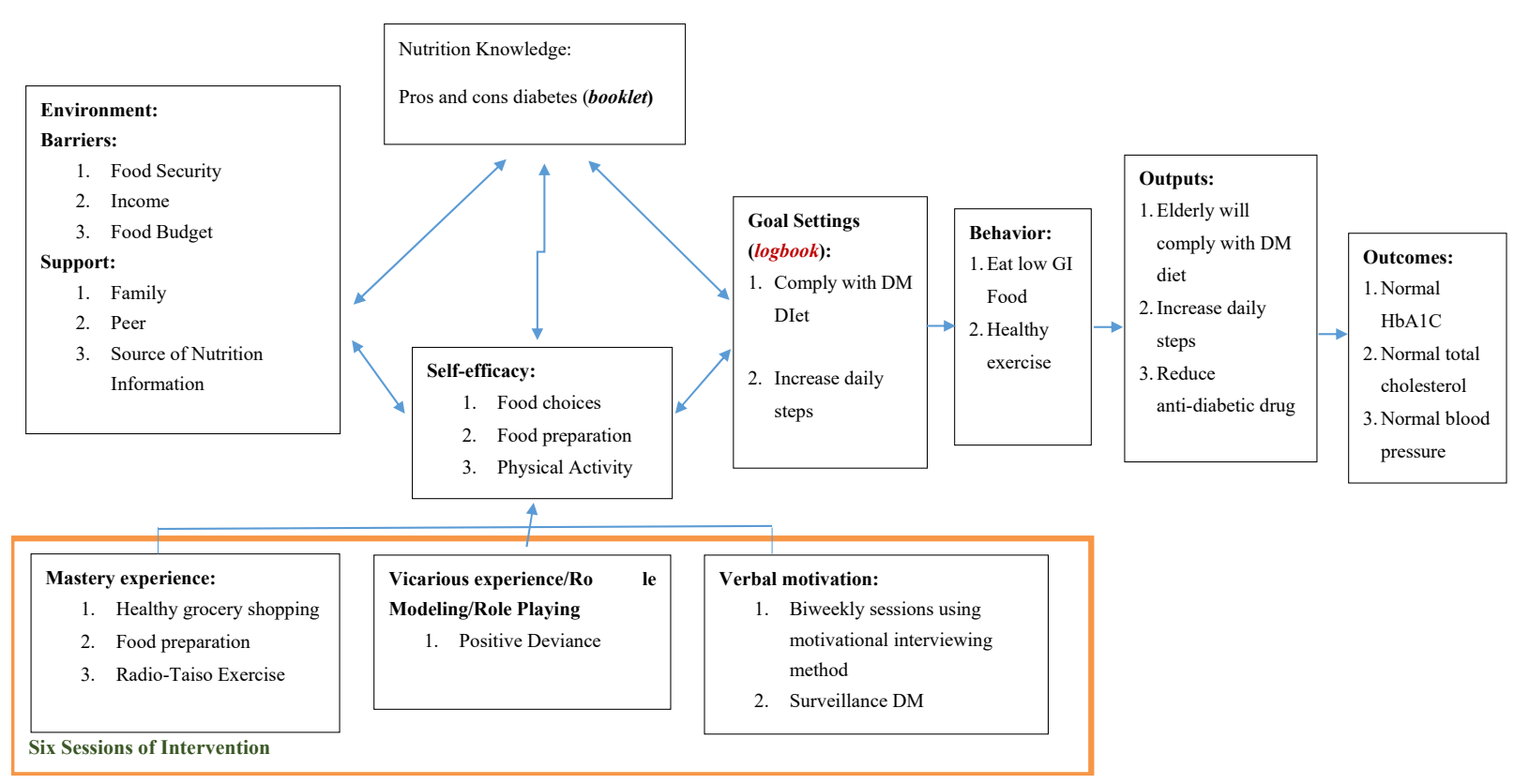

Figure 2. Construct of Iintervention Based on Social Cognitive Theory

The goals of treatment in intervention group was to improve healthy food choices and/or physical activity to maintain $\mathrm{HbA} 1 \mathrm{c}$ and cholesterol level of participants through six session of biweeky nutrition education. To enhance the dietary and/or physical activity adherence, motivational training delivered by trained nutrition students were given in each session. In order to gain commitment of participants, the reward in the form of grocery voucher were given if participants attend minimal 4 times of session consistenly. The full intervention sessions take three months longs with approximate duration as long as 90 for each session. Every session, participants will receive 30 -minute class session, followed by a hands-on activity lasting 30 minutes, and a 30-minutes motivational interview session. The specific theme related to diabetes and dyslipidemia nutritional care strategies focus on traffic light diet were taught every session. The choosen theme was described in Table 1

The hands-on activity was given in the shapes of simple games and simulation to enhance participants' enthusiasm and self confidence toward traffic light diet and physical activity. These activities were designed to enable older people to cope with basic environmental obstacles. The content of the six sessions of nutrition education are outlined in Table 1.

The motivational interviewing was given during the sessions, include providing verbal motivation for older people to achieve their biweekly goals, which centered on improving daily steps, fruit and vegetable intake, and traffic light diet adherence by assist them to deal with overcome barriers. Each motivational interviewing session lasted for approximately 30 minutes. The motivational interviewing session was delivered by a trained nutrition student of Universitas Airlangga. 
Table 1. Intervention Components of Lansia Study

\begin{tabular}{|c|c|c|c|}
\hline $\begin{array}{l}\text { Construct of Social } \\
\text { Cognitive Theory }\end{array}$ & Behavior mechanism impacted & Session & Intervention components \\
\hline $\begin{array}{l}\text { Provide information on } \\
\text { health risk of diabetes and } \\
\text { hypercholesterolemia }\end{array}$ & $\begin{array}{l}\text { Mechanisms affecting belief } \\
\text { formation/cognitive mechanisms } \\
\text { toward elders' nutrition literacy }\end{array}$ & $\begin{array}{l}\text { Session } \\
1-2\end{array}$ & $\begin{array}{l}30-45 \text {-minute nutrition education class } \\
\text { on the introduction on the diabetes } \\
\text { mellitus and its impacts for elderly }\end{array}$ \\
\hline Outcome expectation & $\begin{array}{l}\text { By improving elder's nutrition } \\
\text { literacy, elderly might expect a } \\
\text { healthier lifestyle in order to improve } \\
\text { their physical health (have a good } \\
\text { level of } \mathrm{HbA} 1 \mathrm{C} \text { and total cholesterol }\end{array}$ & $\begin{array}{l}\text { Session } \\
3-4\end{array}$ & $\begin{array}{l}\text { 30-45-minute nutrition education class } \\
\text { on low glycemic index and low } \\
\text { cholesterol traffic light diet followed by } \\
\text { healthy behavior message to improve } \\
\text { elders' fruit and vegetable consumption } \\
\text { and increase elders' daily steps. }\end{array}$ \\
\hline $\begin{array}{l}\text { Environment (food access, } \\
\text { peer support) }\end{array}$ & $\begin{array}{l}\text { With supportive environment, it will } \\
\text { be easier to perform the intended } \\
\text { healthy behavior. }\end{array}$ & $\begin{array}{l}\text { Session } \\
1-6\end{array}$ & $\begin{array}{l}\text { Elders in intervention group gathered } \\
\text { every two weeks during nutrition } \\
\text { education class to provide bonding and } \\
\text { peer support. }\end{array}$ \\
\hline Mastery experience & $\begin{array}{l}\text { Performing intended behavior during } \\
\text { nutrition education class or during } \\
\text { the hands-on activities' session will } \\
\text { improve elderly's self-efficacy for } \\
\text { performing the following behaviors: } \\
\text { 1. Healthy grocery shopping } \\
\text { 2. Food preparation } \\
\text { 3. Physical activity }\end{array}$ & $\begin{array}{l}\text { Session } \\
3 \\
\text { Session } \\
4 \\
\text { Session } \\
1-6\end{array}$ & $\begin{array}{l}\text { 30-minute nutrition education class on } \\
\text { healthy grocery shopping followed by a } \\
\text { 30-minute mock grocery shopping } \\
\text { session. } \\
\text { 20-minute Radio-Taiso session } \\
\text { 30-minutes making menu for elderly } \\
\text { with emphasis on low GI and low } \\
\text { cholesterol food. } \\
\text { 30-minute nutrition education class on } \\
\text { healthy cooking methods followed by a } \\
60 \text {-minute cooking demonstration. }\end{array}$ \\
\hline Goal setting & $\begin{array}{l}\text { Assisted planning and goal setting } \\
\text { will make behavior change perceived } \\
\text { as attainable by elderly }\end{array}$ & $\begin{array}{l}\text { Session } \\
1-6\end{array}$ & $\begin{array}{l}\text { 30-minute hands-on experience on goal } \\
\text { setting to improve physical activity (as in } \\
\text { daily steps), low GI low cholesterol food. }\end{array}$ \\
\hline Vicarious experience & $\begin{array}{l}\text { Hearing testimony from other } \\
\text { participants of how they perform self } \\
\text { efficacy to attain traffic light diet and } \\
\text { physical activity. }\end{array}$ & $\begin{array}{l}\text { Session } \\
6\end{array}$ & $\begin{array}{l}\text { 50-minute nutrition education class on } \\
\text { traffic light diet practice }\end{array}$ \\
\hline Verbal Motivation & $\begin{array}{l}\text { Verbal motivation from a respected } \\
\text { informal leader such as community } \\
\text { health worker will improve elder's } \\
\text { self-efficacy for: } \\
\text { 1. Healthy grocery shopping } \\
\text { 2. Food preparation } \\
\text { 3. Physical activity }\end{array}$ & $1-6$ & $\begin{array}{l}\text { The motivational interviewing delivered } \\
\text { through nutrition sessions and hands on } \\
\text { activity. It will focus on providing verbal } \\
\text { motivation for elders to achieve their } \\
\text { biweekly goals (consisting of improving } \\
\text { daily steps, and comply DM diet), and } \\
\text { help with strategies to overcome barriers. }\end{array}$ \\
\hline
\end{tabular}

\subsection{Control and Comparison Group}

There were two type of comparison groups in this study, the control group, and the education material only group. The control group did not receive any intervention during the study except usual care delivered by local community health workers, and also benefits from a government food supplementation program. The other comparison group, education material only group received the same standard care as control group, coupled with set of printed educational materials. The sets of printed educational materials (booklets) were provided after baseline data measurement for both intervention and comparison group (printed educational material only). All older people 
participating in the study received usual care in the form of monthly health monitoring of their health and nutritional status at posyandu lansia and access to a supplementary feeding program from Surabaya government.

\subsection{Characteristics of the Elderly}

A face-to-face interview with structured questionnaire was performed by trained nutrition students to obtain characteristics of the participants involved in this study such as age, gender, family size, occupantional status, educational attainment, and nutrition literacy Household income and food expenditure were used to estimate socioeconomic status (SES).

\subsection{Health Outcomes}

The primary health outcomes in this study were the change in HbA1C (\%) and total cholesterol $(\mathrm{mg} / \mathrm{dL})$ levels among older people. Details of $\mathrm{HbA1C}$ and total cholesterol measurement was described within the laboratory data section below. Baseline and endline measurement were conducted to measure the change in the health outcomes due to the interventions. Baseline measurement were done a month before the intervention started, and endline measurement was held at the end of intervention (after three months). The same methods of height assessment were used at baseline and endline measurement.

\subsection{Laboratory Data}

Laboratory data include $\mathrm{HbA1C}$ and total cholesterol levels were become primary outcomes in this study. Data collections were performed by health analysts from National Glycohaemoglobin Standardization Program (NGSP) certified laboratory (Prodia ${ }^{\circledR}$ ) in Surabaya city. Whole blood samples were collected from median cubital vein using vacuum syringe as much as $7 \mathrm{cc}$, where $5 \mathrm{cc}$ would use to perform total cholesterol analysis, and the rest of the blood for HbA1C analysis. After the blood collection, the samples were brought to the laboratory in a cooler box with ice gel pack. A trip from research site to the laboratory took the average time of 20 minutes. The centrifugation was done for total cholesterol analysis. The blood samples were centrifudged in $1.8 \mathrm{rcf}$ for 10 minutes using Eppendorf 5702 centrifugation machine. HbA1C were analyzed using ion-exchange HPLC method performed by Variant ${ }^{\mathrm{TM}}$, and total cholesterol used enzymatic colorimetric method performed by Cobas ${ }^{\circledR}$ C501. The analysis was done in the same day with serum collection, and the blood samples were not be stored for future analysis.

\subsection{Anthropometric Data}

The nutritional status was the secondary outcome measured in this study. Anthropometry datas such as weight and height, body composition, as well as waist circumference were collected from eligible participants. The height was measured to the nearest $0.1 \mathrm{~cm}$ using a stadiometer (SECA 213). Participants stand in the stadiometer with frankfurt plane position for height measurement. The body weight along with body composition datas were measured using Omron HBF-375 body fat monitor (Shenzen, China) to $0.01 \mathrm{~kg}$ for weight in light clothing, without shoes or sandals, phone, or other accessories which may interfere the result of measurement. Waist circumference was measured using non-extensible steel tape (MyoTape) with a bare abdomen. The body mass index (BMI) gained in this study will be defined to nutritional status based on WHO BMI for Asian reference standard. The changes of body mass index (BMI) during the study becomes secondary health outcome measured in this study. All anthropometric and body composition measurement was recorded twice to ensure the validity. The third measurement was taken if the difference between the prior two measurement differ by more than $1 \%$.

\subsection{Nutrient Intake}

The average of daily energy and nutrient intakes were generated using the 2 x 24-hour dietary recall in weekend and weekdays. The main nutrients of interest in this study were: energy, protein, fat, cholesterol, and simple sugar taken by the older people. The 24-hour recall interviews were performed by nutrition students whose has been trained before data collection. The training materal including a standardized protocol to ask neutral probing questions to encourage recall of food items and to teach different methods of food preparation and brands available in different cultures. Dietary data were analyzed using Nutrisurvey 2007 software drawing from a database of Indonesian Food updated yearly by the Department of Nutrition, Universitas Airlangga (UA) - Indonesia.

\subsection{Psychological Data}

The adapted questionnaire was arranged from several source to develop a 30-item questionnaire that is used to measure expected behavior of low fat and glycemic index food intake as well as physical activity among participants. The 7-d behavior questionnaire (SIT-Q-7d) were used to assess older people's daily sedentary behavior and sitting time. An instrument to assess self-efficacy was developed based on Bandura's guide. All selfefficacy questionnaires in this study was using likert scale to measure the confidential level of participants in 
dealing with barriers and performing specific task including self efficacy toward barrier to physical activity and fruit and vegetables consumption (in accordance 10-item, 6-item, 8-item questionnaire); self efficacy toward performing physical activity, and also fruit and vegetable consumption (8-item, 6-item and 8-item questionnaires, respectively). For all psychological variables we tested the Cronbach alpha prior to data analysis to test the internal consistency.

\subsection{Statistical Analysis Plan}

All collected data in this study was analyzed using IBM Statistic 23 (Armonk, NY) software. The normal distributed or transformed datas was analyzed using mixed factorial ANOVA in order to test the difference between groups. For non-normal distributed data, two related-samples Mann Whitney U with Bonferroni correction was performed. The significance level for this study set at alpha 0.05 .

\section{Discussions}

This study aimed to assess the effectiveness of the Low Fat and Glycemic Index in the form of Traffic Light Diet intervention in conjunction with Radio-Taiso for enhancing HbA1C and total cholesterol levels in older people. The class sessions, hands-on activity, along with motivational interviewing were hypothesized to result in beneficial effect for the respondents through enhancement of self-efficacy in modifying diet and physical activity. The intervention sessions was held every two weeks and this approach was expected to magnify the effect of behaviorally oriented nutrition education.

The involvement of Posyandu Lansia as part of this research has become one kind of strength for the study. Posyandu Lansia is a community self-help activity which may gather its member everyweek routinally. The Posyandu Lansia conduct a routine elderly health check-up together with Jagir Public Health Center, so the chance to collect preeliminary data and conduct continous monitoring are highly possible. The existence of Posyandu Lansia also allows ease of dissemination of research finding. Although Surabaya is a large urban city, but the population demography living there might be different from any other city in Indonesia. Surabaya population mostly consisted of Javanese and Maduranese ethnic where Indonesia have more that 300 ethnicities. The different area and ethnic might resulted in different food pattern and barrier of dietary and physical activity modification.

The developed treatment intends to modify health behaviour beyond biweekly goal setting and self-efficacy to attain engaged goals. The encouragement to fullfil the goals was given by class sessions, hands-on activity, and verbal motivation. The effect of behavior modification was assessed by anthropometric and biochemical measurement. In order to reduce bias, the anthropometry measurement was done three times. A clustered random sampling was performed to reduce selection bias. Also, to anticipate bias, during data collection and interventioan, blinding will be done to the participants, health worker, and outcome assessor (enumerators and laboratory assessors) during the study. Due to behavior related changes that did not result any negative effect, unblinding is not permissable.

\section{Acknowledgments}

The authors thank the head of the Public Health Center (Puskesmas) in Jagir Sub-District, for their assistance in delivering the intervention. The authors would also extend the gratitude to all elderly and Posyandu cadres in Jagir sub-district that involved in this study. This study was fully funded internally by the International Research Grant Program from Faculty of Public Health Universitas Airlangga. Publication of this article was funded in part by the Universitas Airlangga Open Access Publishing Fund. The funding was not interfering the study design. However, the researchers obligated to give regular monitoring and evaluation report to the funding agency every three months during the study.

\section{Competing Interests Statement}

The authors declare that there are no competing or potential conflicts of interest.

\section{References}

Aune, D., Norat, T., Leitzmann, M., Tonstad, S., \& Vatten, L. J. (2015). Physical activity and the risk of type 2 diabetes: a systematic review and dose - response meta-analysis. European Journal of Epidemiology, 30(7), 529-542. https://doi.org/10.1007/s10654-015-0056-z

Badan Pusat Statistik. (2014). Statistik Penduduk Lansia. Jakarta: Badan Pusat Statistik.

Badan Pusat Statistik Kota Surabaya. (2015). Surabaya Dalam Angka 2014. Surabaya.

Baker, P., \& Friel, S. (2014). Processed foods and the nutrition transition: evidence from Asia. https://doi.org/10.1111/obr.12174 
Bandura, A. (1989). Human agency in social cognitive theory. Am Psychol. https://doi.org/:10.1037/0003066X.44.9.1175

Basu, S., Stuckler, D., Mckee, M., \& Galea, G. (2012). Nutritional determinants of worldwide diabetes: an econometric study of food markets and diabetes prevalence in 173 countries. Public Health Nutrition, 16(1), 179-186. https://doi.org/10.1017/S1368980012002881

Brand-Miller, J., Hayne, S., Petocz, P., \& Colaiguri, S. (2003). Low - Glycemic Index Diets in the A meta-analysis of randomized controlled trials. Diabetes Care, 26(8), 2261-2267. https://doi.org/10.2337/diacare.26.8.2261

Cooper, A. J. M., Brage, S., Ekelund, U., Wareham, N. J., Griffin, S. J., \& Simmons, R. K. (2014). Association between objectively assessed sedentary time and physical activity with metabolic risk factors among people with recently diagnosed type 2 diabetes. Diabetologia, 57, 73-82. https://doi.org/10.1007/s00125-013-30698

Departemen Kesehatan Republik Indonesia. (2015). Pelayanan dan Peningkatan Kesehatan Usia Lanjut. Jakarta: Depkes RI.

Drichoutis, A. C., Lazaridis, P., \& Nayga, R. M. (2006). Consumers' use of nutritional labels: A review of research studies and issues. Academy of Marketing Science Review, 9(9), 1-22.

Frost, G., Wilding, J., \& Beecham, J. (1994). Dietary Advice Based on the Glycaemic Index Improves Dietary Profile and Metabolic Control in Type 2 Diabetic Patients. Diabetic Medicine, 11, 397-401. https://doi.org/10.1111/j.1464-5491.1994.tb00292.x

Goff, L. M., Cowland, D. E., Hooper, L., \& Frost, G. S. (2013). Low glycaemic index diets and blood lipids: A systematic review and meta-analysis of randomised controlled trials. Nutrition, Metabolism and Cardiovascular Diseases, 23(1), 1-10. https://doi.org/10.1016/j.numecd.2012.06.002

Hu, F. B. (2003). Sedentary lifestyle and risk of obesity and type 2 diabetes. Lipids, 38(2), 103-108.

Hu, F. B. (2011). Globalization of Diabetes The role of diet, lifestyle, and genes. Diabetes Care, 34(6), 1249-1257.

International Diabetes Federation. (2015a). Diabetes Prevalence: Indonesia. USA.

International Diabetes Federation. (2015b). Diabetes Prevalence: Thailand. USA.

Kawagoe, T., Nagata, H., Shobuda, Y., Ueda, M., Tominaga, R., Kuga, H., ... Kobayoshi, T. (2010). Effect of limbering up exercise to prevent falls on physical performanceand fall risks in elderly workers. In International Conference on Fall Prevention and Protection (pp. 69-72). US Department of Health and Human Service.

Kurniawan, I. (2010). Diabetes Melitus Tipe 2 pada Usia Lanjut. Majalah Kedokteran Indonesia, 576-584.

Ludwig, D. S. (2002). The Glycemic Index: Physiological Mechanisms Relating to Obesity, Diabetes, and Cardiovascular Disease. Journal of The American Medical Association, 287(18), 2414-2423. https://doi.org/10.1001/jama.287.18.2414

Popkin, B. M., Adair, L. S., \& Ng, S. W. (2013). of Obesity in Developing Countries. 70(1), 3-21. https://doi.org/10.1111/j.1753-4887.2011.00456.x.NOW

Rasiah, R., Thangiah, G., Yusoff, K., Manikam, R., Chandrasekaran, S. K., Mustafa, R., \& Bakar, N. B. A. (2015). The impact of physical activity on cumulative cardiovascular disease risk factors among Malaysian adults. BMC Public Health, 15(1), 1242. https://doi.org/10.1186/s12889-015-2577-5

Shi, L., Shu, X. O., Li, H., Cai, H., Liu, Q., Zheng, W., ... Villegas, R. (2013). Physical activity, smoking, and alcohol consumption in association with incidence of type 2 diabetes among middle-aged and elderly Chinese men. PloS One, 8(11), 77919.

Siri-Tarino, P. W., Sun, Q., Hu, F. B., \& Krauss, R. M. (2010). Saturated fat, carbohydrate, and cardiovascular disease. The American Journal of Clinical Nutrition, 91(3), 502-509.

VK, S., JK, R., \& R., D. (2014). Rural urban disparity in and around Surabaya region, Indonesia. J Tech Sci, 25(2), 41-49.

Wang, Q., Xia, W., Zhao, Z., \& Zhang, H. (2015). Effects comparison between low glycemic index diets and high glycemic index diets on HbA1c and fructosamine for patients with diabetes: A systematic review and metaanalysis. Primary Care Diabetes, 9(5), 362-369. https://doi.org/10.1016/j.pcd.2014.10.008

Waxman, A. (2005). Why a global strategy on diet, physical activity and health? Nutrition and Fitness: Mental 
Health, Aging, and the Implementation of a Healthy Diet and Physical Activity Lifestyle, 95, 162-166.

WHO. (2011). Non-Communicable Diseases in The South East Asia; 2010 Situation and Responses. Geneva: WHO.

World Health Organization, \& International Society of Hypertension Writing Group. (2003). World Health Organization (WHO)/International Society of Hypertension (ISH) statement on management of hypertension. Journal of Hypertension, 2(11), 1983-1992.

\section{Copyrights}

Copyright for this article is retained by the author(s), with first publication rights granted to the journal.

This is an open-access article distributed under the terms and conditions of the Creative Commons Attribution license (http://creativecommons.org/licenses/by/4.0/). 